\title{
Polychlorinated naphthalenes in farmed Chinese mitten crabs in China: Concentration, distribution and source analysis
}

\author{
Yaxin Wang ${ }^{\mathrm{a}}$, Su Zhang ${ }^{\mathrm{a}}$, Mengdie Fan ${ }^{\mathrm{a}}$, Ruiguo Wang ${ }^{\mathrm{a}}$, Yun Zou ${ }^{\mathrm{b}}$, Peilong Wang ${ }^{\mathrm{a}}, \mathrm{Jie}$ Cheng ${ }^{\mathrm{a}}$, \\ Shujun Dong ${ }^{\text {a, } " ~}$ \\ ${ }^{a}$ Institute of Quality Standards and Testing Technology for Agro-Products, Chinese Academy of Agricultural Sciences, Beijing, 100081, China \\ ${ }^{\mathrm{b}}$ Organic Biological Analytical Chemistry Group, Department of Chemistry, University of Liège, Liège, 4000, Belgium
}

\section{A R T I C L E I N F O}

\section{Keywords:}

Polychlorinated naphthalenes

Chinese farmed crab

Crab food web

Distribution

Risk assessment

\begin{abstract}
A B S T R A C T
Polychlorinated naphthalenes (PCNs) are both highly toxic and bioaccumulative environmental contaminates. Dietary intake is the primary pathway for human exposure to PCNs, and PCN concentrations in aquatic foodstuffs are relatively high. Chinese mitten crab (Eriocheir sinensis) is one kind of popular aquatic foodstuffs in Asian countries. Farmed crabs could exposure to PCNs both through feed and environment. However, information on the occurrence of PCNs in farmed crabs is scarce. The present study investigated 75 PCN congeners in farmed Chinese mitten crabs, crab compound feed and sediments collected from Anhui Province and Shanghai in China. The total PCN concentrations in farmed Chinese mitten crabs from Anhui Province and Shanghai were 11.2-42.2 and 5.46-43.8 pg/g wet weight (ww), respectively. The PCN homologue profiles in crabs from both areas were similar, and both were dominated by di-CNs and penta-CNs. In contrast, lower chlorinated PCNs (di-CNs, tri-CNs and tetra-CNs) were the most common homologues in specimens of crab compound feed and sediment samples, indicating that selective bioaccumulation and metabolism of PCNs might occur in farmed crabs. No regional differences were found in the PCN congener profiles of farmed crabs, feed and sediment samples taken from Anhui Province and Shanghai. An assessment found no significant health risk associated with Chinese exposure to PCNs through farmed Chinese mitten crab consumption.
\end{abstract}

\section{Introduction}

Polychlorinated naphthalenes (PCNs) are a group of halogenated organic compounds comprising 75 congeners, each consisting of two fused aromatic six membered rings and with one to eight chlorine atoms as substituents. In the early 19th century, PCNs were found to exhibit environmental stability and low flammability and to provide excellent insulating performance, and so were widely used as electrical cable insulation materials and flame retardants (Falandysz, 1996). However, the commercial production of these compounds was halted in the 1980s because of their dioxin-like toxicities like hepatotoxicity, immunotoxicity, carcinogenicity, embryoxicity and so on (Falandysz, 1996; Cui et al., 2018). PCNs were included in Annexes A and C of the Stockholm Convention as persistent organic pollutants in 2015 , because they display toxicity, bioaccumulation, persistence in the environment and long-range atmospheric transportation (United Nations Environment Programme (UNEP, 2015). At present, PCNs are still being released to the environment during industrial thermal processes like waste incineration and metal-smelting industries (Liu et al., 2014; Yang et al., 2020).

PCNs can be ubiquitously found in the atmosphere, sediment and biota worldwide, and even identified in Human breast milk and blood (Jin et al., 2019; Li et al., 2020, 2021a). PCN issues have been attracted increasingly attention (Fernandes and Olivero-Verbel, 2020). Human exposure to PCNs are mainly through dietary intake, especially from foodstuffs of animal origin due to the bioaccumulation of PCNs in the food supplying chain (Domingo, 2004; Fernandes et al., 2019; Zacs et al., 2021). It has been reported that PCN concentrations in aquatic foodstuffs were higher than other foodstuffs (Domingo et al., 2003; Fernandes et al., 2010; Zacs et al., 2021). Animal feed intake is an essential pathway for farmed fish exposure to environment contaminants (Hites et al., 2004; Montory and Barra, 2006). Farmed fish could also exposure to environment contaminants through the aquatic environment like water and sediment (Nguyen et al., 2019; Shamshirband

\footnotetext{
* Corresponding author.

E-mail address: dongshujun@caas.cn (S. Dong).
} 
et al., 2019; Das et al., 2020), and environment contaminants in sediments are likely to pose detrimental biological effects on benthic organisms (Chau, 2006; Dong et al., 2021).

Chinese mitten crabs (Eriocheir sinensis) are benthic animals. They are considered as one kind of popular aquatic foodstuffs in Asian countries, leading to the rapid development of a crab farming industry in China (Hoogenboom et al., 2015). The total production of Chinese mitten crab in China in 2018 was as high as $7.57 \times 10^{8} \mathrm{~kg}$ (Dai et al., 2021). According to farming area and output, the main production areas of Chinese mitten crab farming focus significantly, mainly concentrated in six provinces, including Jiangsu, Hubei, Anhui, Liaoning, Jiangxi and Shandong, and the major natural habitats are located within the Yangtze delta (Luo et al., 2019; Dai et al., 2021). The quality of agricultural water has an influence on the quality of the soil as well as the sediment (Asadi et al., 2020; El Behairy et al., 2021). Compared with other freshwater farmed animals, the time span from the fry to the edible stage is relatively long for crabs, and crabs could be exposed to chemical contaminants both in the animal feed and sediment in their immediate habitat (Hoogenboom et al., 2015; Han et al., 2018; Dong et al., 2021). Previous studies have found that different kinds of animal feed contained PCNs, and PCNs in fish meal were higher than other feedstuffs (Guruge et al., 2004; Dong et al., 2018). The contamination of PCNs in freshwater sediment has also been reported (Guo et al., 2013; Zhang et al., 2015). However, the distribution and relationship of total PCN congeners in freshwater farmed crabs, crab feed and crab farm sediment are not clear.

The present work examined PCN contamination in freshwater farmed crabs from Anhui Province and Shanghai of China - both of which are situated in the lower reaches of the Yangtze River. Anhui Province is in the upper reaches of Shanghai. A total of 94 samples were collected from these two areas, comprising either crabs, feed or sediment from the aquaculture environment. Subsequently, isotope dilutionhigh resolution gas chromatography/high resolution mass spectrometry (HRGC/HRMS) was used to identify 75 PCN congeners in these samples. To the best of our knowledge, this is the first study concerning the presence of PCNs in farmed crab. The objectives of this study were: (1) to determine and compare the concentrations and distribution characteristics of PCNs in farmed crabs from the different regions, (2) to investigate potential sources of PCNs in farmed crabs to giving advice on reducing PCN contamination in crabs, and (3) to assess the health risks associated with the human consumption of farmed crabs containing PCNs.

\section{Materials and methods}

\subsection{Samples}

Farmed crab, feed and sediment samples were collected from $36 \mathrm{crab}$ farms (Table S2) in either Anhui Province $(n=22$, from seven cities in Anhui Province) or Shanghai ( $n=14$, from seven districts in Shanghai) during September and October 2019. These farms were located at the lower reaches of the Yangtze River basin, and were among one of the largest crab farms in the city or district. Of the 94 specimens that were collected, 36 were farmed crab samples, 22 were commercial feed and 36 were sediment. The 55 samples that were collected from Anhui Province included 22 farmed crab samples, 11 feed and 22 sediment samples, while the 39 samples from Shanghai comprised 14 farmed crab samples, 11 feed and 14 sediment specimens. Crab and sediment samples were collected from each of the $36 \mathrm{crab}$ farms. Feed samples were collected from 11 farms in Anhui province and 11 farms in Shanghai. Crab sampling were conducted according to standards procedure (Chinese Standards, 2014); Feed samples were collected according to standards procedure (Chinese Standards, 2005) and sediment samples were collected according to standards procedure (Chinese Standards, 2007). These samples could be representative of the selected farm. After being brought to the laboratory, all samples were stored in a refrigerator at $-20{ }^{\circ} \mathrm{C}$ before analysis.

\subsection{Sample pretreatment}

The meat from all crabs at each farm was combined as one sample. The crab and sediment samples were homogenized and freeze-dried before extraction. Following this, 5, 10 and $5 \mathrm{~g}$ aliquots of the freezedried crab, feed and sediment specimens, respectively, were portioned out for analysis. Each sample was mixed with $10 \mathrm{~g} \mathrm{Na}_{2} \mathrm{SO}_{4}$ and then spiked with 1 ng of a ${ }^{13} \mathrm{C}-\mathrm{PCN}$ internal standards (ECN 5102, including CN-27, CN-42, CN-52, CN-67, CN-73, and CN-75); Cambridge Isotope Laboratories, Inc., MA, USA) before being extracted using an accelerated solvent extraction instrument (ASE 350, Dionex, CA, USA), The extraction solvent was a mixture of hexane and dichloromethane $(1: 1, v / v)$. Each extract was cleaned by being passed through an acidic silica gel column to remove the majority of the lipids, followed by further clean up with a multilayer silica gel column and, finally, activated carbon. After purification, the extract was concentrated to $20 \mu \mathrm{L}$ under a flow of nitrogen and then spiked with $1 \mathrm{ng}$ of a second ${ }^{13} \mathrm{C}-\mathrm{PCN}$ injection standard (ECN 5260, including CN-64; Cambridge Isotope Laboratories, Inc., MA, USA) prior to analysis for recovery calculation. We employed the pretreatment method in previous publications (Li et al., 2020), and detailed information on analysis procedures used in the current study are provided in the supplementary material.

\subsection{Instrumental analysis}

A total of 75 PCN congeners were analyzed using HRGC/HRMS (DFS, Thermo Fisher Scientific, Milan, Italy). In this analysis, the congeners were separated on a DB-5MS capillary column $(60 \mathrm{~m} \times 0.25 \mathrm{~mm} \times 0.25$ $\mu \mathrm{m}, \mathrm{J} \& \mathrm{~W}$, Agilent Technologies, CA, USA). The temperature of the injection port was $260{ }^{\circ} \mathrm{C}$ and the carrier gas flow rate was $1 \mathrm{~mL} / \mathrm{min}$, while the injection volume was $2 \mu \mathrm{L}$ and the splitless injection mode was employed. The temperature program comprised an initial $2 \mathrm{~min}$ hold at $80^{\circ} \mathrm{C}$, an increase at $20^{\circ} \mathrm{C} / \mathrm{min}$ to $180^{\circ} \mathrm{C}$ followed by a $1 \mathrm{~min}$ hold, an increase at $2.5^{\circ} \mathrm{C} / \mathrm{min}$ to $280^{\circ} \mathrm{C}$ followed by a $2 \mathrm{~min}$ hold and finally an increase at $10^{\circ} \mathrm{C} / \mathrm{min}$ to $290^{\circ} \mathrm{C}$ with a subsequent 5 min hold. The mass spectrometer was operated using electron impact in the source with the selected ion monitoring mode, and the resolution was adjusted to approximately 10,000 to ensure accurate quantification. Detailed information on the instrumental methods for PCN analysis are described in the supplementary material.

\subsection{Quality control and quality assurance}

All glassware was washed three times with hexane before used and each batch of samples was analyzed separately with a procedure blank to assess any background PCN contamination. PCN standards (CS1-CS7, $0.25-400 \mathrm{ng} / \mathrm{mL}$ ) were injected to make the calibration curve. The $\mathrm{R}^{2}$ of the calibration curves exceed 0.99 . Before each batch of sample analysis, PCN standard (CS3, $2.5 \mathrm{ng} / \mathrm{mL}$ ) was injected to check the calibration curve and instrument response. The limit of detection (LOD) was defined as the amount that gave a signal-to-noise ratio of 3, and the LODs for the farmed crab, feed and sediment samples in this study were determined to be in the ranges of $0.002-0.032,0.007-0.051$ and $0.005-0.086 \mathrm{pg} / \mathrm{g}$, respectively. Specific PCN congeners were identified by comparing the retention times of peaks in sample chromatograms to those of known compounds in standard mixtures. The recoveries of the ${ }^{13} \mathrm{C}$-labeled PCN internal standards from each sample was in the range of $40-110 \%$. Detailed information on individual internal standard is provided in Table S2.

\subsection{Statistical analysis}

PCN congeners display toxicities to dioxins. The toxic equivalent quantities (TEQs) of PCNs can be determined relative to that of 2,3,7,8tetrachlorodibenzo-p-dioxin (TCDD). In this work, TEQ values for the PCN congeners were calculated based on the corresponding dioxin-like 
toxic equivalency factors (TEFs) (Falandysz et al., 2014; Puzyn et al., 2007). The relative TEFs are listed in Table S3.

$T E Q_{\sum P C N s}=\sum\left(C_{i} \times T E F_{i}\right)$

All statistical analyses were performed by R ver. 4.0.2, SPSS 22 and Microsoft Excel 2016. PCN congener levels < LODs were set as LODs for the statistical analysis. The raw data of PCN concentrations was preprocessed through the normalization to sample median, $\log 10$ transformation, and autoscaling prior to the statistical analysis.

\section{Results and discussion}

\subsection{Concentrations and congener profiles of PCNs in crab samples}

The concentrations of the individual PCNs in all crab samples ( $\mathrm{n}=$ 36) were in the range of 5.46-43.8 pg/g ww (mean: $21.3 \mathrm{pg} / \mathrm{g} \mathrm{ww}$ ). The total concentrations of PCNs were in the range of $11.2-42.2 \mathrm{pg} / \mathrm{g} \mathrm{ww}$ (mean: $24.9 \mathrm{pg} / \mathrm{g} \mathrm{ww}$ ) in the Anhui crab samples and 5.46-43.8 pg/g ww (mean: $21.3 \mathrm{pg} / \mathrm{g}$ ww) in the Shanghai specimens. Thus, the levels of PCNs in the crab samples from these two areas were comparable (Fig. 1A). Because there is relatively little information in the literature regarding the amounts of PCNs in crab, we compiled a summary of PCN concentrations previously found in other aquatic organisms for comparison (Table 1). The concentrations of PCNs in the farmed crabs in this study were comparable to those reported in marine seafood from five Korean cities (none detected (ND)- $110 \mathrm{pg} / \mathrm{g} \mathrm{ww}$ ) and in fish from the UK and the European North Atlantic coast (0.7-265 pg/g ww) (Fernandes et al., 2018; Kim et al., 2018), but lower than those found in fish samples from the Great Lakes in Canada (6-6700 pg/g ww) and the Great Lakes and St. Lawrence River (171-7660 pg/g ww) (Gewurtz et al., 2018; McGoldrick et al., 2018).

Among the PCN homologues, the di-CNs, tetra-CNs, penta-CNs and hepta-CNs accounted for more than $85 \%$ of the total PCN concentrations in farmed crabs both from Anhui Province and Shanghai (Fig. 1B). There were some minor differences between the two sources of crab in the PCN homologues. The homological profiles of the PCNs in the Anhui Province crab samples were all dominated by penta-CNs, which accounted for $32 \%$ of the total PCNs. The next most common congeners were the diCNs, tetra-CNs and hepta-CNs, which contributed $20 \%, 20 \%$ and $13 \%$, respectively. In contrast, in the case of the Shanghai samples, di-CNs were the most common homologue, followed by penta-CNs, tetra-CNs and hepta-CNs, and these compounds contributed $34 \%, 23 \%, 21 \%$ and $10 \%$ of the total PCNs, respectively. This data is consistent with the results of a previous study, which showed that penta-CNs were the

(A)

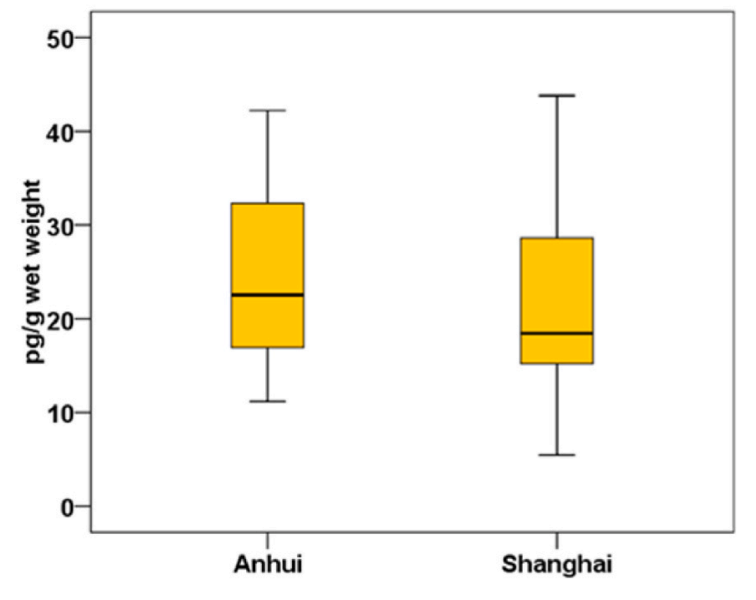

predominant homologues among the tetra-to octa-CNs in fish samples from Korea, followed by tetra-CNs, hexa-CNs and hepta-CNs (Kim et al., 2018). Mono-to octa-CNs were also assessed in lake trout and walleye collected in the Great Lakes, and penta-CNs were found to be dominant in these fish (McGoldrick et al., 2018). Research in China has established that PCNs emitted from the incineration of municipal domestic waste and unintentionally generated as a byproduct of industrial thermal processes (which can possibly form low-chlorine PCN congeners) are the main contributors to the PCNs currently found in the environment (Liu et al., 2014; Yang et al., 2020). The Eastern Seaboard of China has especially dense industrial activity and high population densities (Yang et al., 2020), which suggest that relatively high levels of low-chlorine PCNs could be found in aquatic organisms from lakes in this region. In our present study, di-CNs were the main homologue in the farmed crabs, in agreement with a study of 17 species of fish from the Bohai region in China, which were found to contain primarily di-CNs and tri-CNs (mono-to octa-CNs) (Cui et al., 2018). In the work reported herein, PCN congeners such as CN5/7, 37/33/34, 52/60, 50, 66/67 and 74 were found to be abundant in the crab samples (Figure S1). A prior assessment of marine species at various monitoring locations in the Great Lakes demonstrated that PCN-52/60 was the main compound among the tri-to octa-CNs, which was consistent with the findings of the present study (Blankenship et al., 2000; Helm et al., 2008; McGoldrick et al., 2018). As noted, the congener profiles of the PCNs in the farmed crabs from Anhui Province and Shanghai were similar, but some characteristic congeners were clearly different between these specimens. Specifically, the levels of CN5/7, 3, 28/43 and 53 in the Shanghai samples were higher than those in the specimens from Anhui, for which only the CN18 concentration was higher than in the Shanghai samples ()Figure S2.

\subsection{Source analysis of PCNs in the farmed crab food web}

PCNs were previously been found to be ubiquitous in raw feed materials in China (Dong et al., 2018), and sediment has been identified as the primary source of dioxins in farmed crabs in China (Han et al., 2018). Considering that PCNs and dioxins can both be generated during industrial thermal processes (Liu et al., 2014), PCN levels in farmed crab, feed and sediment were investigated to examine potential sources. Commercial feed is commonly fed to farmed crabs in China, and the PCN concentrations in all 22 feed samples collected from the Anhui Province and Shanghai crab farms were in the range of 20.1-758 pg/g ww (mean: $89.5 \mathrm{pg} / \mathrm{g} \mathrm{ww}$ ). In addition, the total concentrations of PCNs were in the ranges of 20.1-758 pg/g ww (mean: $122 \mathrm{pg} / \mathrm{g} \mathrm{ww}$ ) and 30.3-92.6 pg/g ww (mean: $56.9 \mathrm{pg} / \mathrm{g} \mathrm{ww}$ ) in the Anhui and Shanghai feed specimens.

\section{(B)}

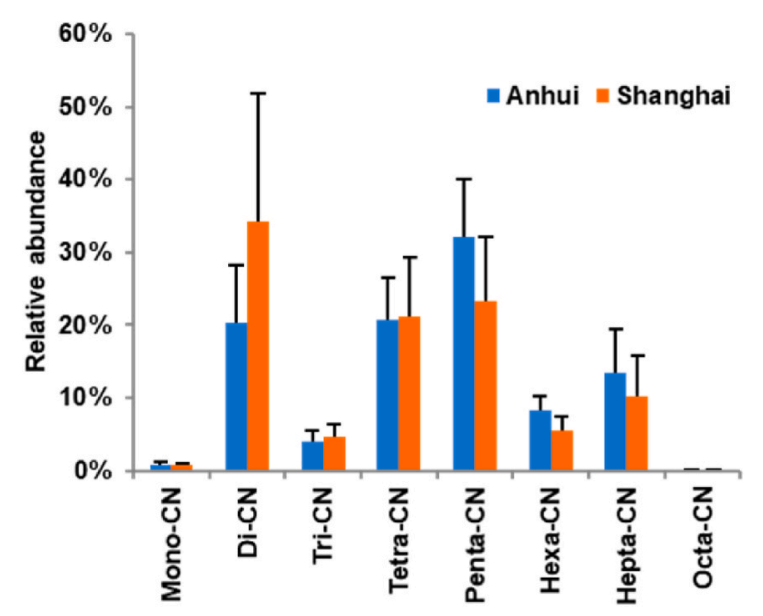

Fig. 1. (A) Concentration ranges and (B) homologue profiles of polychlorinated naphthalenes in farmed crab samples from Anhui Province and Shanghai. 
Table 1

Concentrations of polychlorinated naphthalenes previously reported in aquatic organisms (pg/g wet weight).

\begin{tabular}{|c|c|c|c|c|c|c|}
\hline Region & Collect Year & Sample & Sample number & PCNs & Range/mean & references \\
\hline Five Korean cities & 2012-2013 & seafood species & 33 & 37 & Nd-110 & Kim et al. (2018) \\
\hline the UK marine regions & - & marine fish & 182 & 12 & $0.7-265$ & Fernandes et al. (2018) \\
\hline the Great Lakes & $2006-2013$ & fish species & 18 & 25 & $6-6700$ & Gewurtz et al. (2018) \\
\hline the Great Lakes and St. Lawrence River & 2010-2015 & Lake trout Walleye & - & mono-octa CNs & $171-7660$ & McGoldrick et al. (2018) \\
\hline Bohai & 2014 & Fish & 122 & mono-octa CNs & $7.3-214$ & Cui et al. (2018) \\
\hline the Credit River & 2007 & fish fillets & 11 & - & $50-660$ & Zhang et al. (2016) \\
\hline the UK inland waterways & - & Fish & - & 12 & $48.9-251$ & Rose et al. (2015) \\
\hline Lake Ontario & - & Trout & - & tri-octa CNs & 3500 & Helm et al. (2008) \\
\hline Six cities of Catalonia & 2005 & marine species & 14 & tetra-octa CNs & $2.7-277$ & Llobet et al. (2007) \\
\hline the Great Lakes & 1996-1997 & nine species & 22 & tri-octa CNs & $19-31400$ & Kannan et al. (2000) \\
\hline Anhui Province and Shanghai & 2019 & farmed crab & 36 & mono-octa CNs & $5.46-43.81$ & This study \\
\hline
\end{tabular}

The symbol - indicates that the information was not available in the original publication.

The two highest PCN concentrations were found in feed samples obtained from Anhui Province (758 and $134 \mathrm{pg} / \mathrm{g}$, respectively). The total concentrations of tri-to octa-CNs in feed identified in this study were similar to those reported for cattle, chicken and pig mixed feed samples sourced from Japan (Guruge et al., 2004). The homologue profiles of the PCNs in the present feeds were all dominated by di-CNs, which contributed $69.29 \%$ of total PCNs (Fig. 2A). Similar homologue patterns have been observed in feed ingredients of animal origin, in which di-CNs and tri-CNs were the predominant homologues among the mono-to octa-CNs (Dong et al., 2018). Similarly, lower PCN congeners, such as CN4, 5/7, 6/12, 3, 10 and 24/14, were the dominant PCN congeners in both regions in the present work, with CN5/7 being the most abundant congener in the feed from both areas (Figure S3). These results are consistent with the previous finding that $\mathrm{CN} 5 / 7$ and $\mathrm{CN} 24 / 14$ were the most abundant congeners in feed raw materials used in China (Dong et al., 2018). The congener profiles of PCNs in the feeds from Anhui Province and Shanghai were similar, possibly because these were standard commercial feeds.

As noted, farmed crabs can be exposed to PCNs through their feed intake as well as the aquaculture environment. The PCN concentrations in the 36 sediment samples obtained from Anhui Province and Shanghai were in the range of 4.18-62.1 pg/g dry weight (dw). The total PCN concentrations were in the ranges of 4.82-51.2 pg/g dw (mean: $15.9 \mathrm{pg}$ / $\mathrm{g} \mathrm{dw}$ ) for the Anhui sediment samples and 4.18-62.1 pg/g dw (mean: $37.2 \mathrm{pg} / \mathrm{g} \mathrm{dw}$ ) for the Shanghai specimens. The PCN concentrations were also invariably higher in the sediment samples from the crab farms in Shanghai than those from Anhui Province. The distribution of sources emissions about PCNs showed that the average density of Shanghai industries was higher than Anhui province (Yang et al., 2020). More metal melting plants were located in economic and industrial relatively developed regions in China (Li et al., 2021b). In addition, Shanghai is located at the lower reaches of the Yangtze river and pollutants might bring from upper reaches. The concentrations of PCNs in the sediment samples determined in the present study were lower than those in sediment taken from the Yangtze Estuary (34.3-303.0 pg/g dw) (Guo et al., 2013), Qingdao coastal sea (0.2-1.2 ng/g dw) (Pan et al., 2007) and St. Lawrence River (440-19.300 pg/g dw) (McGoldrick et al., 2018). The mono-to octa-CNs homologue patterns found in all the sediment samples were also similar, with the di-CNs being predominant followed by the tetra-CNs and tri-CNs, which contributed $49 \%, 16 \%$ and $15 \%$, respectively, of the total amounts (Fig. 2B). These results are similar with the prevalence among the tri-to hepta-CNs of the tri-CNs, tetra-CNs and penta-CNs in sediment samples from the Qingdao coastal sea (Pan et al., 2007). In contrast, the hexa-to octa-CNs were predominant in sediment samples from east China (Zhang et al., 2015). The half-lives of tetra- and octa-CNs in soil have been estimated to be more than 182 and 365 days, respectively, implying that the more highly chlorinated PCNs are relatively persistent and can accumulate to higher concentrations in soil and sediment (Zhang et al., 2015). Similarly, because of the accumulation of historic inputs from the chemical industry, the octa- and hepta-CNs were the most prevalent in Lake Ontario sediments (Helm et al., 2008). Such results are in contrast with the apparent higher levels of the lower chlorinated compounds in the present work, possibly as a result of the effects of PCN emissions from municipal sewage and combustion in which PCNs were dominated with lower chlorinated congeners (Zhang et al., 2015; Wang et al., 2016; Cui et al., 2018).

Each of the farmed crab, feed and sediment samples in this survey contained detectable concentrations of PCNs. PCNs can bio-accumulate
(A)

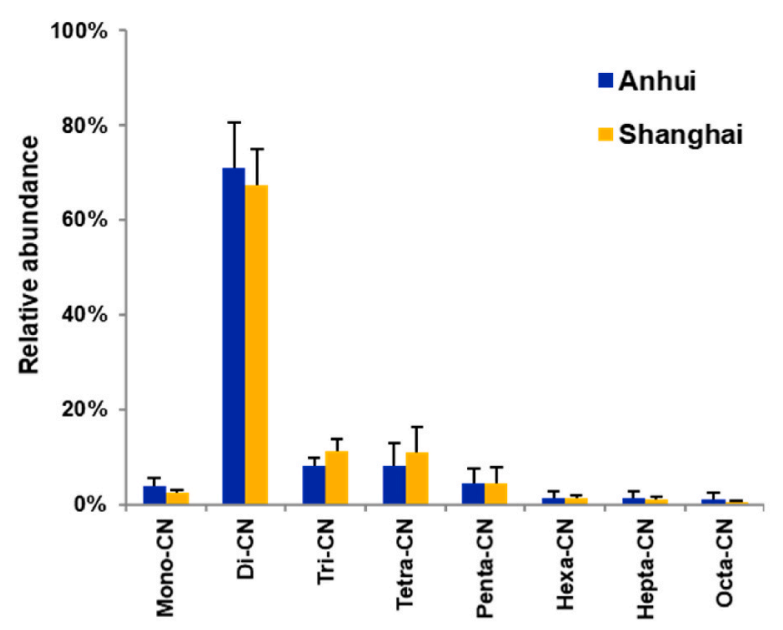

(B)

\section{Sediment}

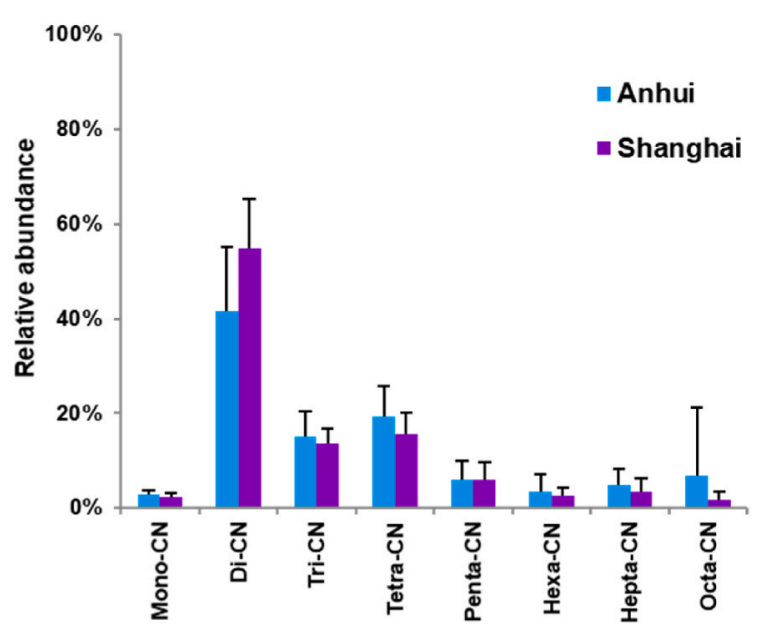

Fig. 2. Polychlorinated naphthalene homologue profiles in compound feed (A) and sediment (B) samples from Anhui Province and Shanghai. 
and farmed crabs are exposed to pond sediment and feed for a prolonged time period. Thus, both feed and sediment might be important sources of PCNs in farmed crabs. PCNs congener profiles are often used to classify the sources of PCNs in food chains, because similar profiles indicate the same sources. For this reason, principal component analysis (PCA) was used to evaluate the sources and correlations of the PCNs in the farmed crab food web samples. Component 1 and component 2 accounted for $42.8 \%$ and $9.3 \%$ (Fig. 3), the PCNs in the crab food web samples from each Anhui Province and Shanghai were not separated from the cluster, indicating that there were no significant differences between the PCN patterns in the farmed crab, feed and sediment samples from these two regions. There was, however, the score plots separated between the three types of specimens because the homologue pattern of them were different with each other. It appears that neither feed nor sediment served as direct sources of PCN contamination in the farmed crabs. Stable isotopes ratio for nitrogen $\left(\delta^{15} \mathrm{~N}\right)$ and carbon $\left(\delta^{15} \mathrm{C}\right)$ were used to investigate the trophic position and food sources in the crab food web in China, and the sediment and crab results were clustered together (Han et al., 2018). Sediment was considered as an important source of dioxins in farmed crabs. Further studies would be conducted to identify the source of PCNs in farmed crabs.

Certain PCN congeners in the farmed crabs varied significantly from those in the feed and sediment samples (Fig. 4). Specifically, the concentrations of $\mathrm{CN} 29$ and 50 in the farmed crabs were higher than those in the feed and sediment, while the concentrations of CN2, 1, 11/8 and 10 were lower in the farmed crabs. It is possible that the PCNs might undergo metabolism in these organisms. As an example, it has been reported that variations in PCN congeners found in fish and in herring gull eggs in the same area of the Great Lakes can be ascribed to metabolic processes that change the bioaccumulation patterns among taxonomic groups (McGoldrick et al., 2018). Considering that the PCN profile in the farmed crabs might have been affected by selective bioaccumulation from the environment and feed, as well as the metabolism of the PCNs and other sources of these compounds in the crab food web, further studies are required.

\subsection{Human exposure to PCNs}

PCNs display similar toxic activity to 2,3,7,8-tetrachlorodibenzo-pdioxin (TCDD) and planar (mono- and non-adjacent substituted) PCBs. In general, they are 3-6 orders of magnitude less potent than TCDD, similar in relative potency to many PCB congeners. Several congeners were assigned a toxic equivalency factor (TEF) to assess the TEQs (Helm et al., 2002; Domingo, 2004; Falandysz et al., 2014). These values corresponded to PCN TEQ concentrations of $0.002-0.014 \mathrm{pg}$ TEQ/g (mean: $0.007 \mathrm{pg}$ TEQ/g) in the case of the Anhui Province crab samples and 0.001-0.007 pg TEQ/g (mean: $0.004 \mathrm{pg}$ TEQ/g) in the Shanghai specimens. The average levels of PCNs in the farmed crab samples from the two regions were comparable, as were the PCN TEQ profiles. These were comparable with the total TEQ values for the mono-to octa-CNs previously found to be in the range of $0.0001-0.009 \mathrm{pg}$ TEQ/g according to a comprehensive survey of 17 species of fish in the Bohai coastal area in China (Cui et al., 2018) and similar data were reported for seafood from local markets in five Korean cities (ND-0.14 pg TEQ/g) (Kim et al., 2018), although lower values were found in marine shellfish in Ireland (0.03 ng TEQ/kg) (Fernandes et al., 2011). Some lower chlorinated PCN congeners were present at relatively high concentration but CN66/67 and 69 contributed almost $65 \%$ of the total PCN TEQs in the crab samples from both areas (Figure S1). This is in keeping with a prior report that CN66/67 and 65/70 contributed almost half the total TEQ in fish from the Bohai coastal area (Cui et al., 2018). The toxicologically dominant PCNs were CN66/67, 68, 69 and 71/72 in fish from inland waterways in the UK, and these values are comparable to the results of this study (Rose et al., 2015).

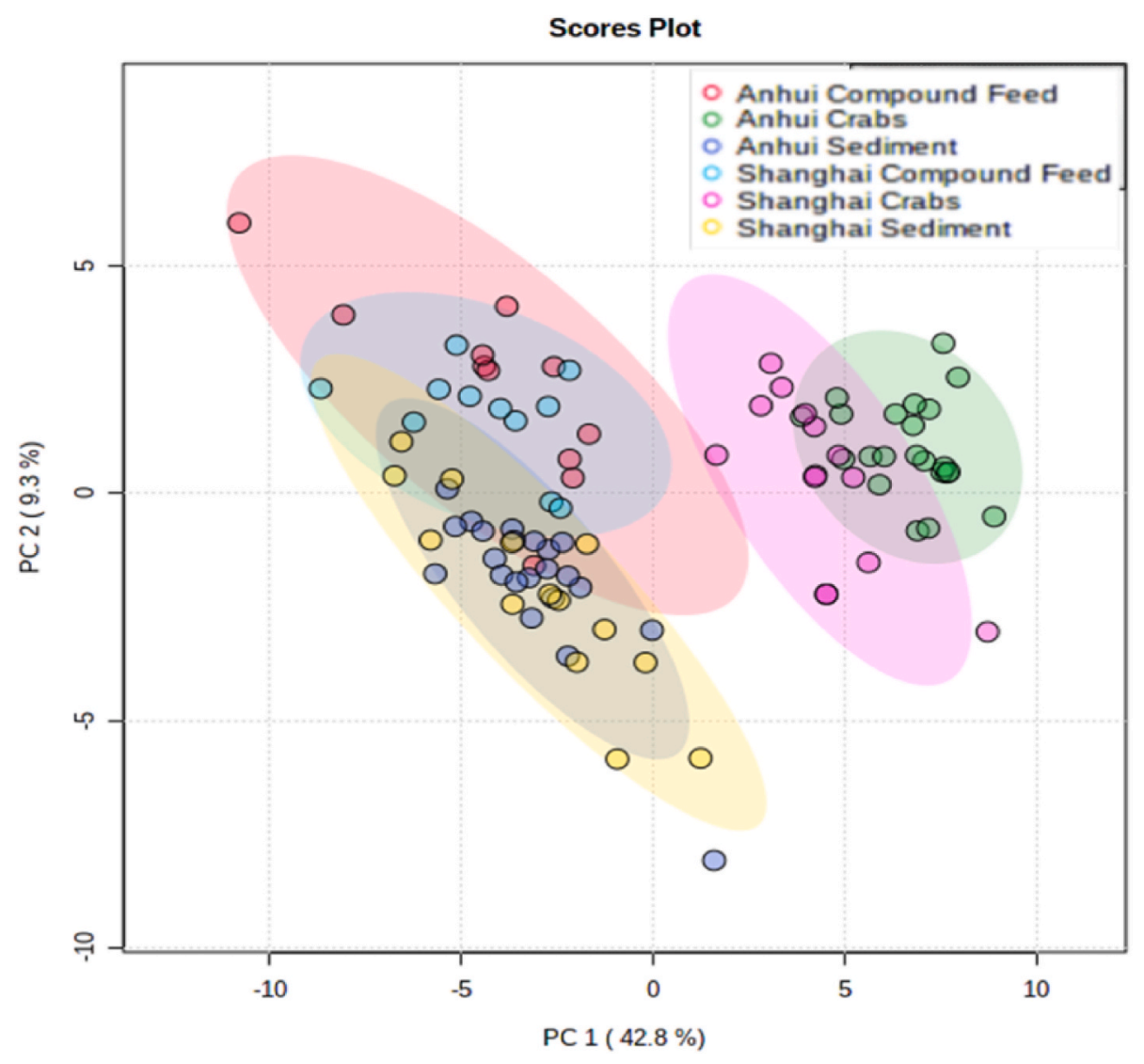

Fig. 3. Principal component analysis of polychlorinated naphthalenes in the crab food web samples. 

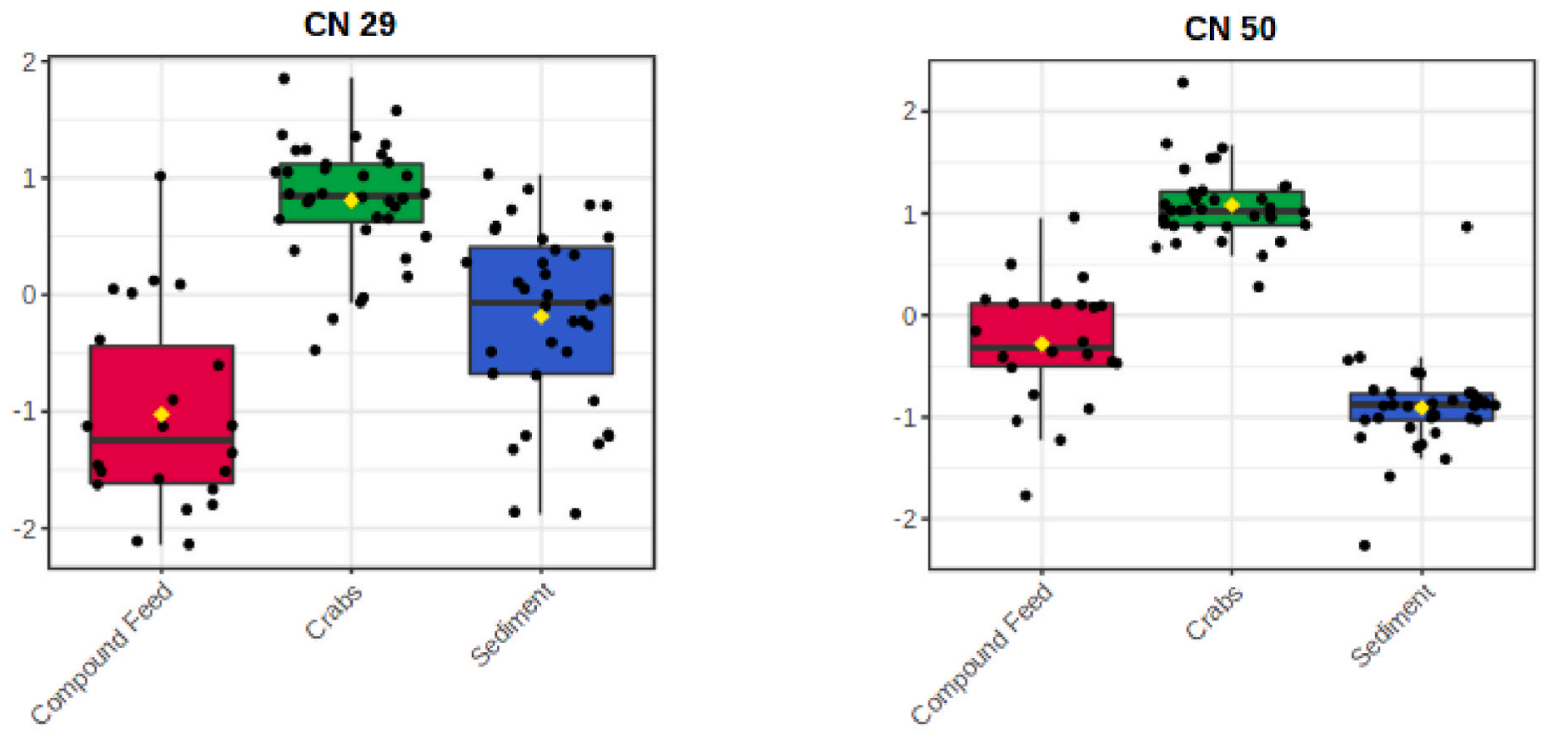

CN 2

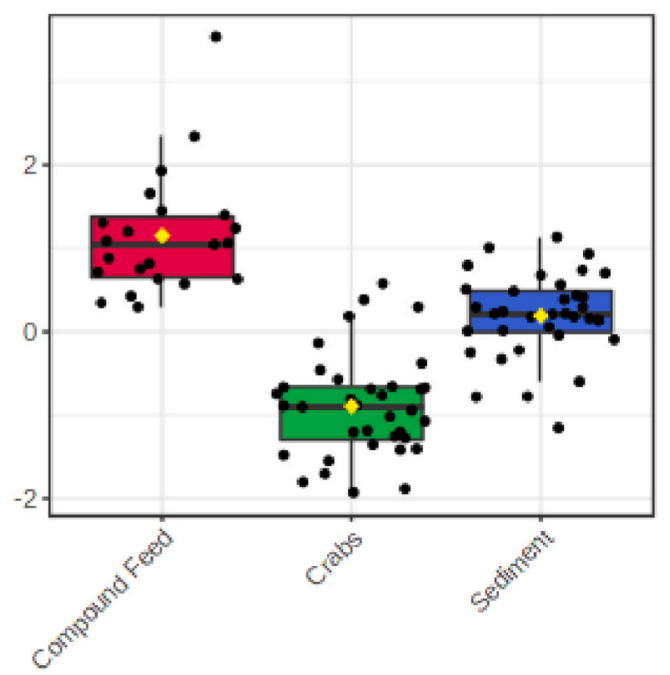

CN 1

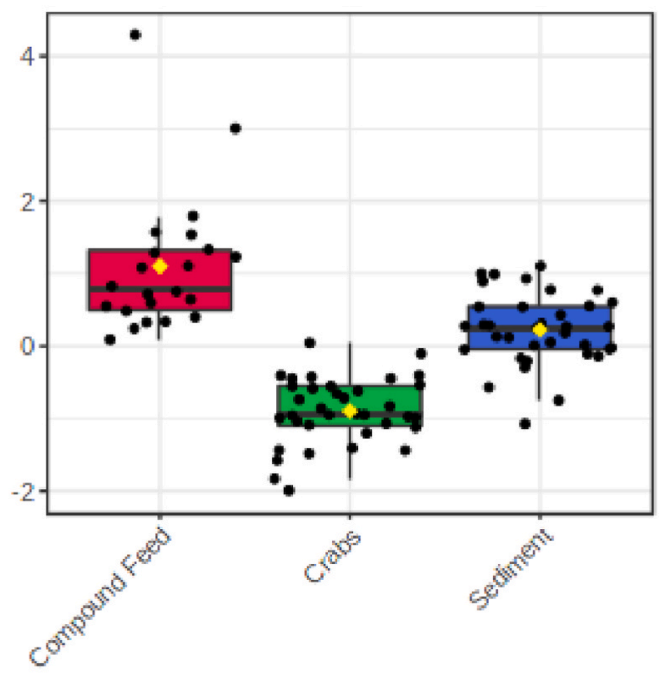

CN $11 / 8$
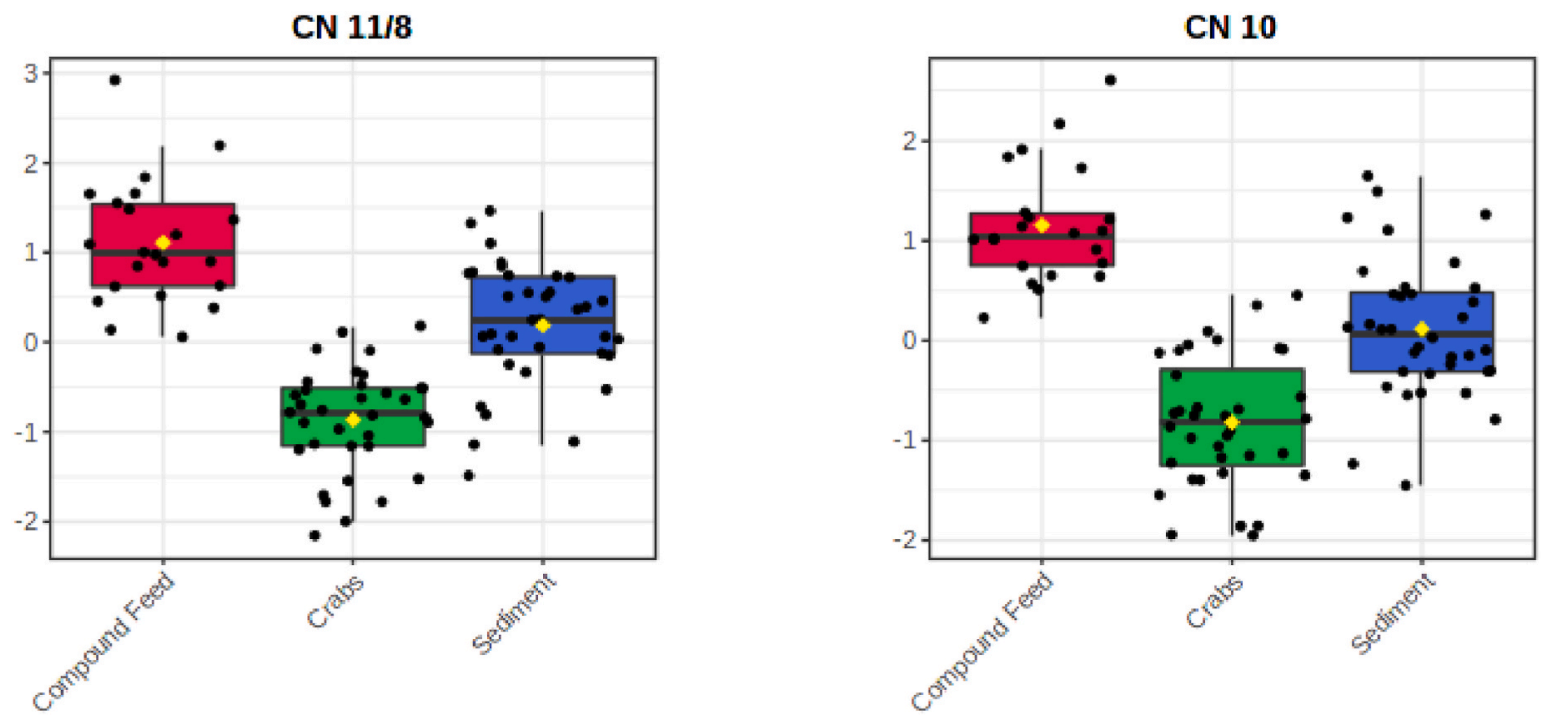

Fig. 4. Polychlorinated naphthalene congeners that varied significantly in farmed crab, compound feed and sediment. 
To assess the dietary exposure to PCNs from crab consumption in the general population, estimated daily intakes (EDIs) were determined from data regarding the daily consumption of aquatic foods in China (Chinese Nutrition Society, 2016). The average EDIs associated with crab consumption were determined to be approximately $0.0044-0.0083$ and $0.0025-0.0048 \mathrm{pg}$ TEQ/ $/ \mathrm{kg}$ body weight (bw)/day for a $63 \mathrm{~kg}$ adult consuming 40-75 $\mathrm{g}$ of aquatic food per day in China (Chinese Nutrition Society, 2016) in Anhui Province and Shanghai. For dioxin-like compounds, the World Health Organization (WHO) recommends maximum EDIs of 1-4 pg TEQ/kg bw/day (WHO, 1998). Thus, even the sample with the highest TEQ content gave an estimated EDI of $0.017 \mathrm{pg}$ TEQ $/ \mathrm{kg}$ bw/day, which equivalent to $1.67 \%$ of the WHO lower limit of $1 \mathrm{pg}$ TEQ/kg bw/day. These results suggest that there are no significant health risks to the Chinese population from the consumption of PCNs in farmed crab. However, PCNs are persistent and can bioaccumulate in the food chain, so it would be desirable to identify the sources of PCNs in farmed crabs.

\section{Conclusions}

PCNs were detected in farmed crabs, feed and sediment samples from crab farms in the lower reaches of the Yangtze River basin. The concentrations and congener profiles of the PCNs in farmed crab samples from Anhui Province were similar with those in specimens taken from Shanghai. The patterns of PCNs in the feed and sediment samples were also similar but quite different from those in the actual crabs. The former was dominated by di-CNs, tri-CNs and tetra-CNs while the latter comprised primarily di-CNs, tetra-CNs and penta-CNs. Differences in metabolic capacity would alter the pattern of bioaccumulation between species groups. In addition, similar to PCBs, lower chlorinated PCNs may be more readily metabolized. These variations are possibly attributed to the selective bioaccumulation and/or metabolism of the PCNs in the farmed crabs or to other sources of PCNs in the farmed crab food web. A health risk assessment indicated that the exposure risk of Chinese consumers to PCNs through farmed crab consumption is not significant. Sediment and crab compound feed were collected in the present study, different types of crab feed might be analyzed and stable isotope ratios would be used to further identify the source of PCNs in farmed crabs. Further studies should also be conducted to investigate the metabolism of PCNs in crabs.

\section{Credit author statement}

Yaxin Wang: Conceptualization, Writing - original draft preparation, Writing - review \& editing, Investigation, Formal analysis. Su Zhang: Data Curation, Validation. Mengdie Fan: Formal analysis. Ruiguo Wang: Conceptualization. Yun Zou: Software. Peilong Wang: Supervision. Jie Cheng: Resources. Shujun Dong: Validation, Writing - review \& editing.

\section{Declaration of competing interest}

The authors declare that they have no known competing financial interests or personal relationships that could have appeared to influence the work reported in this paper.

\section{Acknowledgements}

This study was supported by the National Key Research and Development Program of China (grant no. 2017YFC1600301), the National Natural Science Foundation of China (grant no. 21707164), and the Central Public-interest Scientific Institution Basal Research Fund of the Chinese Academy of Agricultural Sciences (grant no. Y2020PT38). The authors declare they have no conflict of interest.

\section{Appendix A. Supplementary data}

Supplementary data to this article can be found online at https://doi. org/10.1016/j.envres.2021.112582.

\section{References}

Asadi, E., Isazadeh, M., Samadianfard, S., Ramli, M.F., Mosavi, A., Nabipour, N., Shamshirband, S., Hajnal, E., Chau, K., 2020. Groundwater quality assessment for sustainable drinking and irrigation. Sustainability 12, 177.

Blankenship, A.L., Kannan, K., Villalobos, S.A., 2000. Relative potencies of individual polychlorinated naphthalenes and halowax mixtures to induce Ah receptor-mediated responses. Environ. Sci. Technol. 34, 3153-3158.

Chau, K.W., 2006. Persistent organic pollution characterization of sediments in Pearl River estuary. Chemosphere 64, 1545-1549.

Chinese Standards, 2005. Feeding Stuffs-Sampling. GB 14699.1-2005. The National Standards of People's Republic of China (in Chinese).

Chinese Standards, 2007. Sediment Analysis. GB 17378.5-2007. The National Standards of People's Republic of China (in Chinese).

Chinese Standards, 2014. Practice of Sampling Plants for Aquatic Products. GB/T 30891-2014. The National Standards of People's Republic of China (in Chinese).

Cui, L., Wang, S., Gao, L., Huang, H., Xia, D., Qiao, L., Liu, W., 2018. Concentrations and trophic magnification of polychlorinated naphthalenes (PCNs) in marine fish from the Bohai coastal area, China. Environ. Pollut. 234, 876-884.

Dai, H., Sun, Y., Ren, N., Lu, X., 2021. Survey on the current situation of China's Chinese mitten crab industry and analysis of development countermeasures. Jiangsu Agric. Sci. 49, 248-252.

Das, S., Aria, A., Cheng, J., Souissi, S., Hwang, J., Ko, F., 2020. Occurrence and distribution of anthropogenic persistent organic pollutants in coastal sediments and mud shrimps from the wetland of central Taiwan. PLoS One 15, e0227367.

Domingo, J.L., 2004. Polychlorinated naphthalenes in animal aquatic species and human exposure through the diet: a review. J. Chromatogr. A 1054, 327-334.

Domingo, J.L., Falco, G., Llobet, J.M., Casas, C., Teixido, A., Muller, L., 2003. Polychlorinated naphthalenes in Foods Estimated dietary intake by the population of Catalonia ,Spain. Environ. Sci. Technol. 37, 2332-2335.

Dong, S., Li, X., Wang, P., Su, X., 2018. Polychlorinated naphthalene concentrations and distribution in feed raw materials. Chemosphere 211, 912-917.

Dong, S., Zhang, S., Zou, Y., Fan, M., Wang, Y., Cheng, J., Wang, R., Li, T., Li, X., Wang, P., 2021. Concentrations and sources of short- and medium-chain chlorinated paraffins in farmed Chinese mitten crabs in China. J. Hazard Mater. 411, 125076.

El Behairy, R.A., EI Baroudy, A.E., Ibrahim, M.M., Kheir, A.M.S., Shokr, M.S., 2021. Modelling and assessment of irrigation water quality index using GIS in semi-arid region for sustainable agriculture. Water Air Soil Pollut. 232, 352.

Falandysz, J., 1996. Spatial distribution in plankton and bioaccumulation features of polychlorinated naphthalenes in a pelagic food chain in Southern part of the Baltic proper. Environ. Sci. Technol. 30, 3362-3370.

Falandysz, J., Fernandes, A., Gregoraszczuk, E., Rose, M., 2014. The toxicological effects of halogenated naphthalenes: a review of aryl hydrocarbon receptor-mediated (dioxin-like) relative potency factors. J. Environ. Sci. Health. Environ. Sci. Health C. $32,239-272$.

Fernandes, J. Falandysz, Olivero-Verbel, J., 2020. A new focus on legacy pollutants: chlorinated Paraffins (CPs) and Polychlorinated Naphthalenes (PCNs). Chemosphere $238,124580$.

Fernandes, A.R., Tlustos, C., Rose, M., Smith, F., Carr, M., Panton, S., 2011. Polychlorinated naphthalenes (PCNs) in Irish foods: occurrence and human dietary exposure. Chemosphere 85, 322-328.

Fernandes, A.R., Mortimer, D., Gem, M., Smith, F., Rose, M., Panton, S., Carr, M., 2010. Polychlorinated Naphthalenes (PCNs): Congener Specific Analysis, Occurrence in food, and Dietary Exposure in the UK. Sci. Total Environ. 44, 3488-3533.

Fernandes, A.R., Mortimer, D., Holmes, M., Rose, M., Zhihua, L., Huang, X., Smith, F., Panton, S., Marshall, L., 2018. Occurrence and spatial distribution of chemical contaminants in edible fish species collected from UK and proximate marine waters. Environ. Int. 114, 219-230.

Fernandes, A.R., Mortimer, D., Rose, M., Smith, F., Steel, Z., Panton, S., 2019. Recently listed Stockholm convention POPs: analytical methodology, occurrence in food and dietary exposure. Sci. Total Environ. 678, 793-800.

Gewurtz, S.B., Gandhi, N., Drouillard, K.G., Kolic, T., MacPherson, K., Reiner, E.J., Bhavsar, S.P., 2018. Levels, patterns, trends and significance of polychlorinated naphthalenes (PCNs) in Great Lakes fish. Sci. Total Environ. 624, 499-508.

Guo, L., Gao, L., Li, A., Xiao, K., 2013. Polychlorinated Naphthalenes (PCNs) in Surface Sediments of the Yangtze and Yellow River Estuaries, China, vol. 18. Wuhan University Journal of Natural Sciences, pp. 79-87.

Guruge, K.S., Seike, N., Yamanaka, N., Miyazaki, S., 2004. Accumulation of polychlorinated naphthalenes in domestic animal related samples. J. Environ. Monit. 6, 753-757.

Han, Y., Liu, W., Zhu, W., Rao, K., Xiao, K., Gao, L., Su, G., Liu, G., 2018. Sources of polychlorinated dibenzo-p-dioxins and dibenzofurans, and biphenyls in Chinese mitten crabs. Chemosphere 196, 522-530.

Helm, P.A., Bidleman, T.F., Stern, G.A., Koczanski, K., 2002. Polychlorinated naphthalenes and coplanar polychlorinated biphenyls in beluga whale (delphinapterus leucas) and ringed seal (phoca hispida) from the eastern canadian arctic. Environ. Pollut. 119, 69-78.

Helm, P.A., Gewurtz, S.B., Whittle, D.M., Marvin, C.H., Fisk, A.T., Tomy, G.T., 2008. Occurrence and biomagnification of polychlorinated naphthalenes and non- and 
mono-ortho PCBs in lake Ontario sediment and biota. Environ. Sci. Technol. 42, 1024-1031.

Hites, R.A., Foran, J.A., Carpenter, D.O., Hamilton, M.C., Knuth, B.A., Schwager, S.J., 2004. Global assessment of organic contaminants in farmed salmon. Science 303, 226-229.

Hoogenboom, R.L., Kotterman, M.J., Hoek-van Nieuwenhuizen, M., van der Lee, M.K., Mennes, W.C., Jeurissen, S.M., van Leeuwen, S.P., 2015. Dioxins, PCBs and heavy metals in Chinese mitten crabs from Dutch rivers and lakes. Chemosphere 123, 1-8.

Jin, J., Wang, S., Hu, J., Wu, J., Li, M., Wang, Y., et al., 2019. Polychlorinated naphthalenes in human serum samples from an industrial city in Eastern China: levels, sources, and sex differences. Ecotoxicol. Environ. Saf. 177, 86-92.

Kannan, K., Yamashita, N., Imagawa, T., Decoen, W., Khim, J.S., Day, R.M., Summer, C. H., Giesy, J.P., 2000. Polychlorinated Naphthalenes and Polychlorinated Biphenyls in Fishes from Michigan Waters Including the Great Lakes. Environ. Sci. Technol. 34, 566-572.

Kim, J., Shin, E.S., Choi, S.D., Zhu, J., Chang, Y.S., 2018. Polychlorinated naphthalenes (PCNs) in seafood: estimation of dietary intake in Korean population. Sci. Total Environ. 624, 40-47.

Li, C., Zhang, L., Li, J., Min, Y., Yang, L., Zheng, M., Wu, Y., Yang, Y., Qin, L., Liu, G., 2020. Polychlorinated naphthalenes in human milk: health risk assessment to nursing infants and source analysis. Environ. Int. 136, 105436.

Li, C., Li, J., Lyu, B., Wu, Y., Yang, L., Zheng, M., Min, Y., Zhang, L., Liu, G., 2021 a. Burden and risk polychlorinated naphthalenes in Chinese Human milk and a global comparison of human exposure. Environ. Sci. Technol. 55, 6804-6813.

Li, Q., He, L., Wang, Y., Cao, Y., Gao, C., Liu, X., 2021b. Characteristics and distribution of soil contamination at smelting industry sites in China. J. Ecol. Environ. 30, 586-595.

Liu, G., Cai, Z., Zheng, M., 2014. Sources of unintentionally produced polychlorinated naphthalenes. Chemosphere 94, 1-12.

Llobet, J.M., Falco, G., Bocio, A., Domingo, J.L., 2007. Human exposure to polychlorinated naphthalenes throughthe consumption of edible marine species. Chemosphere 66, 1107-1113.

Luo, R., Jiang, T., Chen, X., Zheng, C., Liu, H., Yang, J., 2019. Determination of geographic origin of Chinese mitten crab (Eriocheir sinensis) using integrated stable isotope and multi-element analyses. Food Chem. 274, 1-7.

McGoldrick, D.J., Pelletier, M., de Solla, S.R., Marvin, C.H., Martin, P.A., 2018. Legacy of legacies: chlorinated naphthalenes in Lake Trout, Walleye, Herring Gull eggs and sediments from the Laurentian Great Lakes indicate possible resuspension during contaminated sediment remediation. Sci. Total Environ. 634, 1424-1434.
Montory, M., Barra, R., 2006. Preliminary data on polybrominated diphenyl ethers (PBDEs) in farmed fish tissues (Salmo salar) and fish feed in Southern Chile. Chemosphere 63, 1252-1260.

Nguyen, T.X., Nguyen, T.N., Tran, H.T.T., Le, T.T., Trinh, T.T., Trinh, T.T., Tu, M.B., Cao, N.D.T., Vo, H.D.T., 2019. The interactive effect of the season and estuary position on the concentration of persistent organic pollutants in water and sediment from the Cua Dai estuary in Vietnam. Environ. Sci. Pollut. Control Ser. 26, 10756-10766.

China Nutrition Society, 2016. Chinese Dietary Guidelines. People's Medical Publishing House.

Pan, J., Yang, Y.L., Xu, Q., Chen, D.Z., Xi, D.L., 2007. PCBs, PCNs and PBDEs in sediments and mussels from Qingdao coastal sea in the frame of current circulations and influence of sewage sludge. Chemosphere 66, 1971-1982.

Puzyn, T., Falandysz, J., Jones, P.D., Giesy, J.P., 2007. Quantitative structure-activity relationships for the prediction of relative in vitro potencies (REPs) for chloronaphthalenes. J. Environ. Sci. Health A. 42, 573-590.

Rose, M., Fernandes, A., Mortimer, D., Baskaran, C., 2015. Contamination of fish in UK fresh water systems: risk assessment for human consumption. Chemosphere 122, 183-189.

Shamshirband, S., Nodoushan, E.J., Adolf, J.E., Manaf, A.A., Mosavi, A., Chau, K., 2019. Ensemble models with uncertainty analysis for multi-day ahead forecasting of chlorophyll a concentration in coastal waters. Eng. Appl. Comput. Fluid Mech. 13, 91-101.

UNEP, 2015. Stockholm Convention on Persistent Organic Pollutants.

Wang, M., Liu, W., Hou, M., Li, Q., Han, Y., Liu, G., Li, H., Liao, X., Chen, X., Zheng, M., 2016. Removal of polychlorinated naphthalenes by desulfurization and emissions of polychlorinated naphthalenes from sintering plant. Sci. Rep. 6, 26444.

WHO, 1998. Assessment of the Health Risk of Dioxins: Re-evaluation of the Tolerable Daily Intake (TDI).

Yang, L., Zheng, M., Zhu, Q., Yang, Y., Li, C., Liu, G., 2020. Inventory of polychlorinated naphthalene emissions from waste incineration and metallurgical sources in China. Environ. Sci. Technol. 54, 842-850.

Zacs, D., Perkons, I., Pasecnaja, E., Bartkevics, V., 2021. Polychlorinated naphthalenes (PCNs) in food products in Latvia: congener-specific analysis, occurrence, and dietary exposure of the general population. Chemosphere 264, 128460.

Zhang, L., Zhang, L., Dong, L., Huang, Y., Li, X., 2015. Concentrations and patterns of polychlorinated naphthalenes in surface sediment samples from Wuxi, Suzhou, and Nantong, in East China. Chemosphere 138, 668-674.

Zhang, X., Gandhi, N., Bhavsar, S.P., 2016. Persistent organohalogens in paired fish fillet and eggs: implications for fish consumption advisories. J. Agric. Food Chem. 64, $2832-2840$. 